\title{
Gamification in project management
}

\author{
Ricardo Pateiro Marcão*, Gabriel Pestana, and Maria José Sousa
}

Laureate International Universities,Baltimore (Maryland), United States of America

Universidade Europeia, Lisbon, Portugal, Altran Portugal, S. A.Lisbon, Portugal

*Corresponding author: Ricardo Pateiro Marcão, ricardo.pateiro.marcao@gmail.com

\begin{abstract}
The area of monitoring and project management presents a collection of methodologies. Some are more sequential and others more iterative, each one with benefits in different aspects. In this way, it is intended to gather a set of good practices of project management, identifying the most beneficial characteristics of different methodologies. Since one of the dimensions of project management is the management of human resources, it is urgent to value the motivation of employees. Since in many of the developed studies, the performance of the employee appears as a variable dependent on motivation, it becomes urgent to identify concepts that allow addressing it, such as the concept of gamification. By monitoring the evolution of the performance of each employee, we were able to evaluate the success of the model. Although there are several methodologies in the market, none of them results from a symbiosis between traditional and iterative methodologies, and there is no reference to any model that can dynamically address the employee's motivation. This document focuses on the literature review of the theme of monitoring and project management, whereas the focus is on the concept of gamification as the engine of motivation and the monitoring of the performance of employees, as members of a project team.
\end{abstract}

Keywords: gamification; management; methodologies; monitoring; motivation; performance; project management

\section{Introduction}

Scientific research topic in question focuses on three areas: i) monitoring and project management, ii) gamification as motivation engine and iii) performance monitoring, which will be described according to the perspectives of different authors throughout this chapter. These areas are addressed sequentially because of their interdependence. 


\section{Project management}

Project management is one of the core areas in the development and management of information systems, which may be associated with different methodologies, where agile methodologies stand out, presents by IO4PM ${ }^{1}$. According to T. C. S. Machado et al ${ }^{2}$, this type of methodologies aims to turn the effort invested in a project into profit so that high quality products or services can be achieved in the shortest possible time, minimizing the time spent producing documentation. Scrum Framework is an example of an agile and highperformed methodology. However, these types of methodology are often hard to apply to organizations due to the high investment required. The Scrum Framework is always accompanied by an Agile Manifesto, which defines the characteristics of the model, emphasizing principles of i) individual and iterative interactions about processes and tools, ii) production of documentation about application modules, iii) collaboration methods and iv) planning of response to requests for change of scope of the project in progress. These principles were synthesized by J. Sutherland, et al. ${ }^{3}$ to help organizations developing complex projects, in which it is aligned with the project management book of knowledge (PMBOK). Only methodologies and frameworks aligned with PMBOK can form project management tools. This provides rules, guidelines and characteristics for project management, in global standards and regardless of sector, allowing the process defined by T. C. S. Machado et al ${ }^{2}$ : i) define and authorize the project in a given area, ii) define and refine the scope of the project and plan the activity necessary to achieve the desired goal, iii) train the team so that the project management plan is followed, iv) monitor the evolution of the project, allowing corrective actions to take plan, and v) formalizing the completion of the project through its acceptance by all stakeholders. According to this process, it covers nine areas of knowledge: i) integration management, ii) scope management, iii) time management, iv) cost management, v) quality management, vi) human resources management, vii) communication management, viii) risk management and ix) procurement management, says $P M I^{4}$.

In order to turn the Scrum Framework into a simpler, faster and cheaper approach, T. C. S. Machado et al $^{2}$ have developed a methodology on the framework and practices of project management institute (PMI), based on the verbal decision analysis, which, in turn, relies on the resolution of multicriteria problems through its qualitative analysis.

This allows for knowledge creation, namely about the decision context, and therefore increases the decision-making confidence. To achieve this, a questionnaire was developed for Scrum Masters, one of the certifications offered by the Scrum Alliance and the International 
Scrum Institute, aiming to characterize each Scrum approach quantitatively, using tools such as ORCLASSWEB, ORCLASS and ZAPROS-LM. a study that revealed that project management based on the Scrum Framework emphasized the efficiency and effectiveness demonstrated by the Scrum Masters teams surveyed, although many software companies still find it difficult to implement such functional practices.

Reference $N$. Kaleshovska et al. ${ }^{5}$ developed an empirical study on project monitoring and management, focused on achieving a benchmark using the Scrum approach for project management, in order to identify the most common reasons of failure. According to the authors, the use of agile methodologies has increased over the last decade and has proved to be a powerful alternative methodology to traditional information systems development, capable of avoiding standard problems in project management such as i) delays in development, (ii) high costs and (iii) lack of staff motivation. For a project to be successful, it is necessary to meet all the requirements defined according to the four dimensions present in the project management triangle (see Fig. 1). A deviation in the project base would be enough to compromise the success of the project and, depending on the constraints set and the proportion of the deviation identified, the project could result on its success or partial failure. According to StangishGroup ${ }^{6}$, the use of the Scrum Framework enabled a 23\% increase in the project success; an increase of $10 \%$ in the capacity of handling the different project challenges; and a reduction of 13\% in the committed projects between 1994 and 2012, resulting in (i) poor definition of requirements or incomplete requirements, (ii) lack of involvement of the team with the business (12.4\%), and (iii) lack of resources (10.6\%), which are easily solved through the use of agile methodologies, due to its flexibility and responsiveness that allows to forward, as we can analyze in Table 1.

\section{Gamification as a motivation driver}

The choice of the methodology for monitoring and project management is not the only point that we can use to deduce its efficiency, especially in what concerns to the area of knowledge related to human resources management according to $P M I^{4}$, where management is focused on the motivation and expectations of the project team. Because of this, we will consider the concept of gamification as the motor of motivation. According to M. Saileret et al. ${ }^{7}$, the main objective of the concept of gamification is to enhance the motivation of the human being and to improve his performance in a given activity. A study developed by him also reveals that it is through the configuration of the different variables that may be involved in the game design that is possible to fulfill the basic biological needs of the employee, and it has been verified that this approach positively affects satisfaction and performance. Reference $S$. Deterding et 
al. ${ }^{8}$ also consider that the motivation is leveraged by the systematic addition of benefits to the employee, dependent on the results obtained in the projection and development of products or services, transforming the professional activity into a game. However, ${ }^{9}$ propose a new definition of the concept of gamification, emphasizing the experimental nature of gaming and gamification themselves rather than their systematic understanding. The concept of gamification refers to a process that allows the improvement of a service through the creation of value triggered by the employee himself, which constitutes a starting point for the research work in the above. In Table 2, we can analyze the definitions presented for the concept of gamification, according to the levels of abstraction considered. For this empirical work, we will consider the definition of $K$. Huotari et al. ${ }^{9}$, based on the experiences of the collaborator, on the second level of abstraction.

In order to understand how social factors predict attitude towards gamification and intention to continue using gamification services, as well as the intention to recommend such services, J. Hamari et al. ${ }^{10}$ conducted a study through the application of a survey of systems, whose conceptual map of research work can be seen in Fig. 1.

Table 1- Comparison between the waterfall methodology and the scrum framework, according to $N$.

Kaleshovska et al. ${ }^{5}$

\begin{tabular}{|c|c|c|}
\hline \multirow{2}{*}{ Description } & \multicolumn{2}{|l|}{ Methodologies } \\
\hline & Waterfall & Scrum \\
\hline $\begin{array}{l}\text { Definition of the development process of } \\
\text { the information system }\end{array}$ & During project start-up & $\begin{array}{l}\text { During project planning and } \\
\text { closure phases }\end{array}$ \\
\hline Budgeting and project end date & $\begin{array}{l}\text { Determined in the project } \\
\text { planning phase }\end{array}$ & $\begin{array}{l}\text { Determined throughout the } \\
\text { project }\end{array}$ \\
\hline Engagement of the collaborator & Casual & Throughout the project \\
\hline $\begin{array}{l}\text { Flexibility and creativity in the context of } \\
\text { the project team }\end{array}$ & Limited & Unlimited during interactions \\
\hline $\begin{array}{l}\text { Moment of knowledge transfer in the } \\
\text { context of the project team }\end{array}$ & Start of the project & Throughout the project \\
\hline $\begin{array}{l}\text { Probability of success of information } \\
\text { systems projects }\end{array}$ & Low & High \\
\hline
\end{tabular}

Table 2- Levels of abstraction that can be applied in the two definitions of gamification presented by $K$.

Huotari et al. ${ }^{9}$

\begin{tabular}{|l|l|l|}
\hline \multirow{2}{*}{ Level of abstraction } & Conditions & Experiential \\
\cline { 2 - 3 } I & Systematic & $\begin{array}{l}\text { Games require the voluntary } \\
\text { involvement of employees }\end{array}$ \\
\hline II & Games are the system & Generates hedonic pleasure \\
\hline
\end{tabular}




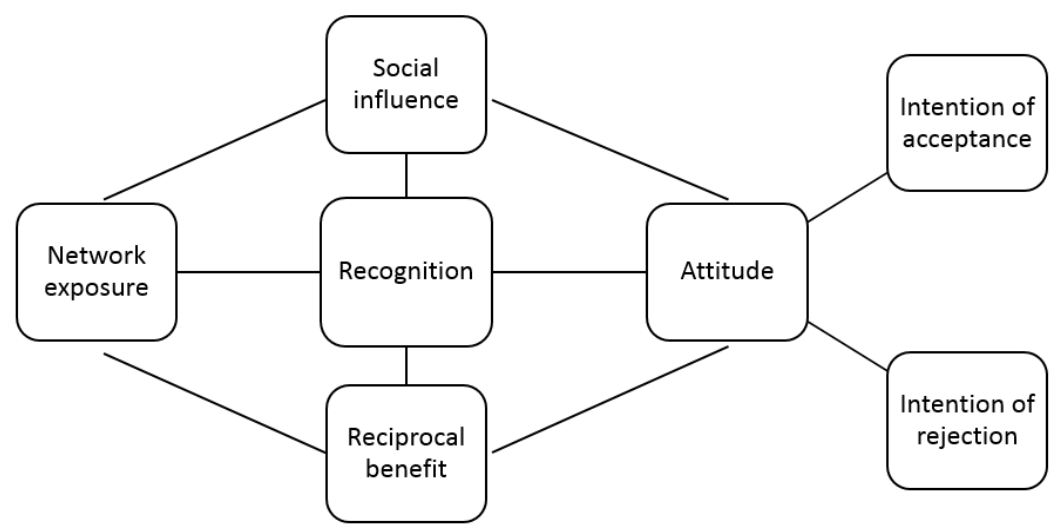

Fig. 1-Influence of motivational indicators on the gamification concept (adapted from[10] ${ }^{10}$ )

The results of the application of this study indicate that, although the relationships were positively influenced by the degree of employee exposure, the "amount of recognition" they receive does not directly affect their attitudes towards the use of gamification services. Therefore, the researchers conclude that the attitude towards the use of a gamified service is determinant in the intention to use and, consequently, in its recommendation, which confirms the role of the different attitudes shown in the justification of behavioral intentions, says $I$. Ajzen et al. ${ }^{11}$. According to K. Huotari et al. ${ }^{9}$, social elements are essential for the creation of services or products gamified.

According to $N$. Chandler et al. ${ }^{12}$, the use of the gamification concept in the development of products and services reflects a very useful trend in the opinion of chief information officers (CIOs) and other IT managers in the near future. A successful example is what was done by Sweden's National Society for Road Safety and Volkswagen. They implemented the Speed Camera Lottery, a lottery in which drivers who respected the speed limit automatically participated, the premium being paid through the excess fines speed, exemplify I. Blohm et $a^{13}{ }^{13}$.

According to I. Blohm et al. ${ }^{13}$, the potential of the gamification concept is based on motivational support, distinguished by R.M. Ryan et al. ${ }^{14}$ in two types: i) intrinsic and ii) extrinsic. Intrinsic motivation is directly rooted in a given task, while extrinsic motivation targets external goals as financial compensation. In the context of the above research, the motivation is the intrinsic motivation, aiming at i) increasing employee satisfaction, ii) transmitting optimism to colleagues, iii) social interaction, and iv) interpretation of the concept of gamification applied to their work. Reference I. Blohm et al. ${ }^{13}$ also make an analogy between the definition elements of the game to be simulated and the reasons 
associated with each type of element, according to the mechanical and dynamic perspectives, as we can see in Table 3.

Table 3- Elements of game definition and their motivations, according to I. Blohm et al. ${ }^{13}$

\begin{tabular}{|l|l|l|}
\hline \multirow{2}{*}{ Motivation } & Game definition elements \\
\cline { 2 - 3 } & Game mechanics & Game dynamics \\
\hline Intellectual curiosity & Documentation about behavior & Exploration \\
\hline Achievement & Scoring systems and awards & Collection \\
\hline Social recognition & Rankings & Competition \\
\hline Final goal & Levels and reputation & Status acquisition \\
\hline Social exchange & Group Tasks & Collaboration \\
\hline Cognitive stimulation & Pressure and challenges & Challenge \\
\hline Self-determination & Characters and world/ virtual trading & Development/ organization \\
\hline
\end{tabular}

\section{Performance monitoring}

Although we want to use motivation as input for the project management methodology we intend to define, it is necessary to understand how we can monitor employee performance. Even though the use of game elements in gammoned professional settings is very extensive, there are not many studies about their relationship with performance evolution, say M. Ninaus et $a .^{15}$. According to researchers at the Instituto Superior Técnico, elements such as progress bars and positioning indicators at different levels could be useful for monitoring the evolution of employee's performance. In order to validate this premise, two test groups were used, one with visibility of the mentioned elements and the other with no such visibility, showing an exponential progression of their results in the group whose visibility is available, revealing that the concept of gamification influences performance.

However, there are studies on monitoring performance progress in different environments. Reference $J$. Lee et $a l .{ }^{16}$ conducted a study that resulted in the proposal of an online monitoring method for fault detection with the aim of improving the performance of a factory. This is based on the multivariate statistical control process, which allows to calculate the value of the statistical monitoring, through observation at certain time intervals. Considering two states of the process: i) controlled and ii) uncontrolled. The controlled state is assigned when the statistical value is within the limits; the uncontrolled is assigned when it exceeds this value. The statistical control process uses two control algorithms: the local outlier factor (LOF) and the independent component analysis (ICA); which allow the detection of discrepant or antagonistic faults. In the control process, we take $t$ as the time index, $d(t)$ as 
the observed monitoring function, obtained in real time, is (t) $=\{$ normal, missing $\}$ as the process state function. The purpose of monitoring is to consider the state of the current process s (t) correctly. Parallel to this scheme, there is a monitoring process, proposed by $J$. $J$. Downset al. ${ }^{17}$ and deepened by T. McAvoy et al. ${ }^{18}$, used in optimization, predictive control, diagnostic process, etc., which was used as monitoring process of test for the previously proposed scheme (Tennessee Eastman (TE)). This last one is no more than a set of business rules characterized by event condition action (ECA), which, in turn, categorize the type of possible faults in the manufacturing process.

Another concept related to the topic above is the Business Activity Monitoring (BAM), studied by a group of researchers in Germany and Austria, aiming to analyze the influence factors that would affect the performance of the business processes, in order to obtain a continuous observation of KPIs. When key performance indicators (KPIs) do not meet the required target values, business analysis takes into account the factors that cause this deviation. Their work was based on the development of a framework for the monitoring and analysis of these factors, dispersing it in different layers: i) monitoring and ii) execution of the business process. With this framework, in addition to providing up-to-date dashboard information about the performance of the current process, it is possible to make the so-called benchmark analysis, affecting the main factors that influence the business process and which prevent the achievement of the desired performance, result mapped on a decision tree, conclude B. Wetzstein et al. ${ }^{19}$.

Despite the technological advances of science and the ease of use of technology by each individual, there is still some reluctance regarding privacy and ethical cohesion's issues, which means that acceptance of science and technology is never complete. We can think of the different positive examples of its usefulness, as we have described in the previous paragraphs, but by wearing intelligent houses, the picture may not look so well painted. According to a study conducted by P. Panek et al. ${ }^{20}$, the use of ambient assistant living (AAL) systems, particularly by older people, offers enormous potential in increasing their safety and quality of life despite the reluctance and anxiety caused by the feeling of living in a kind of Big Brother environment. This study allowed to evaluate the possible conflicts arising between technology, acceptance, ethics and privacy, using the universe of the senior residences with AAL systems. The authors proposed the design of different prototypes, based on sensors and reactors, regarding the monitoring of human behavior, which was not well accepted by the study population. Many citizens see technology as positive, but anxiety and 
the possible lack of ethics in the moral issue dominate them. According to the certificate of use of the prototypes, it is necessary to sacrifice some privacy to gain security. Privacy may be jeopardized by the maintenance of other interests, such as law and order or the reasonable distribution of social benefits and costs. However, for political, psychological and social reasons, privacy is something that should be valued and not subjugated by economic-financial indicators. For these and other reasons, only light and temperature sensors were used, and they were chosen to be placed next to the switches. After its application, the trends of the senior population were analyzed, which proved to be very useful in the detection of suspicious deviations, which is also important for the measurement of the prototype. The consequences of using the data in the wrong way are concerned, but after a few bursts, users have come to accept the technology without such concern, says $P$. Panek et al. ${ }^{20}$.

When making an analogy to the theme of performance management, it should be borne in mind that not all professionals in the information systems sector can be comfortable with the daily monitoring of their activity, so it is necessary to carefully identify the appropriate indicators of analysis. According to G. Indelicato et al. ${ }^{21}$, there are two basic premises that guide project management, KPIs and other metrics, as well as dashboards: i) the information must be correctly presented, with the correct content, to the correct person and in the correct time; and (ii) it is not possible to correct or improve what is not actually identified or quantified. Since it is necessary to define the scope, time and cost of a project so that its health can be measured, the author focuses on the concept of a critical success factor (CSF) as the indicator that best measures the intended results, controlling the project life cycle. In many situations, tactics are focused on metrics, concluding that this is the best way to ensure that the organization's strategic alignment is aligned with its value.

\section{References}

1. IO4PM, "Project management revealed", International Organization for Project Management, 2016.

2. T. C. S. Machado, P. R. Pinheiro, In. Tmanini, "Project management aided by verbal decision analysis approaches: a case study for the selection of the best scrum practices”, International Transactions in Operational Research, 22(2), 2015, pp. 287 312.

3. J. Sutherland, K. Schwaber, "The scrum papers: nuts, bolts and origins of an agile proces”, 2007. 
4. PMI, "Project management body of knowledge (PMBOK)", Project Management Institute, 2007.

5. N. Kaleshovska, K. Postolov, Z. Janevksi, S. Josimovski, L. P. Ivanovska et al., "Contribution of scrum in managing successful software development projects", Economic Development, (1 - 2), 2015, pp. 175 - 194.

6. StangishGroup, "CHAOS manifesto - think big, act small”, Volume 176, The Standish Group International, Inc, 2013.

7. M. Sailer, J. U. Hense, S. K. Mayr, H. Mandl, "How gamification motivates: an experimental study of the effects of specific game design elements on psychological need satisfaction”, Computers in Human Behavior, 2016.

8. S. Deterding, D. Dixon, R. Khaled, L. Nacke, "From game design elements to gamefulness: defining gamification”, Proceedings of the $15^{\text {th }}$ International Academic MidTrek Conference: Envisioning Future Media Environments, pp. 9 - 15, ACM, 2011.

9. K. Huotari, J. Hamari, "Defining gamification: a service marketing perspective", Proceedings of the $16^{\text {th }}$ International Academic MindTrek Conference, pp. $17-22$, ACM, 2012.

10. J. Hamari , J. Koivisto, "Social motivations to use gamification: an empirical study of gamifying exercise”, European Conference on Information Systems, p. 105, 2013.

11. I. Ajzen, "The theory of planned behavior", Organizational behavior and human decision processes, 50 (2), pp. 179 - 211, 1991.

12. N. Chandler, B. Hostmann, G. Herschel, "Gartner's business analytics framework”, Gartner Group, Research ID (G00219420), 2011.

13. I. Blohm, J. M. Leimeister, "Design of it-based enhancing services for motivational support and behavioral change”, Business \& Information Systems Engineering, 5(4), pp. $275-278,2013$.

14. R.M. Ryan, E.L. Deci, "Intrinsic and extrinsic motivations: classic definitions and new directions”, Contemporary Educational Psychology, 25 (1), pp. 54 - 67, 2000.

15. M. Ninaus, G. Pereira, R. Stefitz, R. Prada, A. Paiva, C. Neuper, G. Wood, "Game elements improve performance in a working memory training task”, IJSG, 2 (1), pp. 3 - 16, 2015.

16. J. Lee, B. Kang, K. Shin, S. Kang, "Online process monitoring scheme for fault detection based on independent component analysis (ICA) and local outlier factor 
(LOF)”, Computers and Industrial Engineering (CIE), 40 ${ }^{\text {th }}$ International Conference on CIE, pp. 1 - 6, IEEE, 2010.

17. J. J. Downs, E. F. Vogel, “A plant-wide industrial process control problem”, Computers \& chemical engineering, 17 (3): pp. 245 - 255, 1993.

18. T. McAvoy, N. Ye, "Base control for the Tennessee Eastman problem", Computers \& Chemical Engineering, 18 (5), pp. 383 - 413, 1994.

19. B. Wetzstein, P. Leiner, F. Rosenberg, I. Brandic, S. Dustdar, F. Leymann, "Monitoring and analyzing influential factors of business process performance", Enterprise Distributed Object Computing Conference, EDOC’09, IEEE International, pp. 141 - 150, IEEE, 2009.

20. P. Panek, W.L. Zagler, "A living lab for ambient assisted living in the municipality of schwechat”, International Conference on Computers for Handicapped Persons, pp. 1008 - 1015, Springer, 2008.

21. G. Indelicato, "Project management metrics, KPIs and dashboards: a guide to measuring and monitoring project performance”, Project Management Journal, 43 (2), p. 102, 2012. 